\title{
A decade of gains in public health emergency preparedness and response at points of entry
}

\author{
Shahrokh Roohi ${ }^{a}$ and Todd Wilson ${ }^{a}$ \\ Correspondence to Shahrokh Roohi (e-mail: sroohi@cdc.gov).
}

he role of air travel in rapid translocation of infectious disease is indisputable. ${ }^{1}$ The global health community has long been concerned about the movement across borders of vaccinepreventable diseases, tuberculosis and other diseases of public health concern. These concerns escalated following the September 2001 terrorist attack and the anthrax bioterrorism incident in the United States of America; the worldwide spread of severe acute respiratory syndrome (SARS) in 2003; and the reemergence of H5N1 avian influenza soon thereafter, which stoked fears about the possibility of a severe influenza pandemic. To better prepare and coordinate countries to respond to all-hazards health emergencies at their borders, in the past 10 years the global public health community has formed numerous domestic and international alliances.

In the international arena, country public health officials contributed to the revision of the World Health Organization (WHO) International Health Regulations. Prior to the 2005 revision, Member States were required to report cholera, plague and yellow fever. The revised regulations ${ }^{2}$ are risk-based rather than prescriptive and mandate the recognition and notification of any unusual public health event or emergency of international concern that meets certain criteria, including biological, chemical and radiological risks. As a result, much has been done to strengthen core public health capacities and preparedness for emergency response at points of entry and exit, contributing to community and global health security. Additionally, international partners supported the United Nations International Civil Aviation Organization's Cooperative Arrangement for the Prevention of Spread of Communicable Disease through Air Travel. Through this collaboration, Member States engaged in planning for communicable disease response at airports, including drills, exercises and response coordination between the aviation and public health sectors. Furthermore, to facilitate the sharing of information and expertise, public health officials supported the WHO Ports, Airports and Ground Crossings Network (PAGNet). This network provides a forum to address international travel health and transport issues in real time. PAGNet members and WHO regional staff meet periodically for training and information sharing. Topics of discussion include preparedness at air, sea and land points of entry and exit, and coordination of response between governmental entities. Another noteworthy effort is the Global Health Security Initiative. The participants in this group, which include the health ministers of Canada, France, Germany, Italy, Japan, Mexico, the United Kingdom and the United States of America, as well as the European Commission and WHO officials, work to strengthen global preparedness for pandemics and bioterrorism.

Within the United States of America, governmental interagency planning efforts in the past decade have bolstered emergency preparedness planning, trainings, drills and exercises at the 20 points of entry that receive about $80 \%$ of inbound international airline passengers. These collaborations were energized in 2003 post-SARS, redoubled in 2006 through the development of response plans for communicable diseases in airline passengers and further expanded in 2009 by adding a passenger health screening component.

Because of these and related collaborations in the last decade, coordination between border health authorities has improved markedly in addressing travel and points-of-entry public health issues. In 2009, the H1N1 influenza pandemic tested the world's preparedness with its rapid spread across the globe from 
its origin in North America. The public health community ably responded at international borders by issuing travel advisories and health information for travellers and implementing health declarations, contact tracing or screening in some cases. ${ }^{3}$

Within the United States of America, border planning efforts also improved readiness and coordination for other unanticipated public health emergencies. Examples include the border public health response to the 2010 Haiti earthquake and the subsequent cholera outbreak, the Fukushima Daiichi nuclear power plant accident caused by the 2011 Great East Japan Earthquake, the repatriation of citizens during these disasters and the communication of health risk to travellers following the global resurgence of measles in 2011.

Clearly, much progress has been achieved in preparedness and response planning in the last decade, although more remains to be done, especially as it relates to improving linkages between domestic and global health security. ${ }^{4}$ However, in an era of budget cutting and global austerity, we may be at risk of slipping backward. Progress can be undermined if health authorities fail to connect the dots between border health and traditional public health activities. Border planning, training and exercise activities, along with timely cross-fertilization of ideas and information sharing can protect the health of the travelling public. This in turn can mitigate the burden of disease in the travellers' destination communities during global outbreaks.

Moving forward, it is essential that the international border health community facilitate dialogue on research, evaluation, publication of data and discourse on published reports with differing conclusions and recommendations on border measures. This will help unify our understanding of the role that border interventions can play under different circumstances and promote balanced and evidence-based decision-making. More work remains to be done in defining benchmarks for preparedness, metrics for impact, use of risk assessment to inform decision-making and the establishment of scientific guiding principles for just-in-time decisionmaking on when to initiate and end border measures. Without agreed-upon scientific principles, definitions and performance standards, it will be difficult to measure our progress and prioritize future programmatic and scientific investments.

Throughout recorded history, travel has been a major factor in the spread of disease. This will continue to be the case in the foreseeable future given the volume and speed of travel, the just-in-time global shipping of goods and the limited availability of local commercial supplies. Early detection, rapid public health response, and all-hazards coordination for biological, zoonotic, chemical and radiological incidents at our borders are more important now than ever. We must therefore continue to learn from and expand upon the gains we have made in the past decade by advancing the evaluation of border public health activities, publishing border intervention data and sharing lessons learnt on all-hazards public health emergency preparedness and response.

\section{Disclaimer:}

The findings and conclusions in this report are those of the authors and do not necessarily represent the official position of the United States Department of Health and Human Services or the Centers for Disease Control and Prevention.

\section{References:}

1. Institute of Medicine. Infectious disease movement in a borderless world. Washington, DC: The National Academies Press; 2010.

2. International health regulations (2005). Geneva, World Health Organization Press, 2008 (http://whqlibdoc.who.int/ publications/2008/9789241580410 eng.pdf, accessed on 8 December 2011).

3. World Health Organization. Public health measures taken at international borders during early stages of pandemic influenza $\mathrm{A}(\mathrm{H} 1 \mathrm{~N} 1)$ 2009: preliminary results. Weekly Epidemiological Record, 2010, 85 (21):185-196. pmid:20514731

4. Khan A. Public health preparedness and response in the USA since 9/11: a national health security imperative. The Lancet, 2011, 378(9794):953-956. doi:10.1016/S01406736(11)61263-4 pmid:21890060 